\title{
Rates of asthma attacks in patients with previously inadequately controlled mild asthma treated in clinical practice with combination drug therapy: an exploratory post-hoc analysis Robert W Dal Negro1, Luis Borderias², Qiaoyi Zhang33, Tao Fan*3, Vasilisa Sazonov ${ }^{3}$, Magda Guilera ${ }^{4}$ and Stephanie D Taylor ${ }^{3}$
}

Address: ${ }^{1}$ Bussolengo Gen. Hospital, Verona, Italy, ${ }^{2}$ San Jorge Hospital, Huesca, Spain, ${ }^{3}$ Merck \& Co, Inc., Whitehouse Station, NJ, USA and ${ }^{4}$ HOREurope, Barcelona, Spain

Email: Robert W Dal Negro - rdalnegro@ulss22.ven.it; Luis Borderias - lborderias@separ.es; Qiaoyi Zhang - qiaoyi_zhang@merck.com; Tao Fan* - tao_fan@merck.com; Vasilisa Sazonov - vasilisa_sazonovkocevar@merck.com; Magda Guilera - mguilera@hor-europe.com; Stephanie D Taylor - Stephanie_taylor@merck.com

* Corresponding author

Published: 30 March 2009

BMC Pulmonary Medicine 2009, 9:10 doi:10.1 I86/147|-2466-9-10
Received: 27 February 2008

Accepted: 30 March 2009

This article is available from: http://www.biomedcentral.com/I47/-2466/9/10

(c) 2009 Dal Negro et al; licensee BioMed Central Ltd.

This is an Open Access article distributed under the terms of the Creative Commons Attribution License (http://creativecommons.org/licenses/by/2.0), which permits unrestricted use, distribution, and reproduction in any medium, provided the original work is properly cited.

\begin{abstract}
Background: Differences could exist in the likelihood of asthma attacks in patients treated with inhaled corticosteroid (ICS), long-acting beta-agonist (LABA), and montelukast (MON) (ICS/LABA/ MON) and patients treated with an inhaled corticosteroid (ICS) and montelukast (MON) (ICS/ MON).

Methods: This was a post-hoc analysis of a pretest-posttest retrospective cohort study. Patients with mild persistent asthma and allergic rhinitis, who were taking an ICS either alone or in combination with a LABA, started concomitant MON treatment as part of their routine care. Rates of asthma- and allergic rhinitis-related medical resource use in the 12-months after the initial (index) MON prescription were compared in the ICS/MON and ICS/LABA/MON groups. An asthma attack was defined as an asthma-related hospitalization, ER visit, or use of an oral corticosteroid.
\end{abstract}

Results: Of the total of 344 patients, I8I (53\%) received ICS/MON and I63 (47\%) received ICS/ LABA/MON in the post-index period for means of 10.5 and II.4 months, respectively, $(\mathrm{P}<0.05)$. Short-acting beta-agonists were used by $74.6 \%$ in the ICS/MON and $71.8 \%$ in the ICS/LABA/MON groups ( $P>0.05)$. An asthma attack occurred in $4.4 \%$ of the ICS/MON group and $6.8 \%$ of the ICS/ LABA/MON group $(P>0.05)$. The adjusted odds of an asthma attack in the post-index period in the ICS/LABA/MON group relative to the ICS/MON group was 1.24 , 95\% confidence interval 0.35 4.44 .

Conclusion: In this observational study of combination drug treatment of mild persistent asthma and allergic rhinitis, no difference was observed between LABA/ICS/MON combination therapy and the ICS/MON combination without LABA use, for the rate of asthma attacks over one year. 


\section{Background}

The precise roles of drug combinations in the management of asthma and allergic rhinitis remain uncertain [1] The recommended maintenance therapies for persistent asthma include inhaled corticosteroids (ICSs), leukotriene modifiers, and long-acting beta-agonists (LABAs). ICSs are the preferred initial therapy for persistent asthma [1]. Leukotriene modifiers, including montelukast (MON), are recommended for mild persistent asthma, as add-on therapy to ICSs for moderate persistent asthma, or as an alternative maintenance therapy for patients unable to tolerate ICSs $[2,3]$, and are also effective against comorbid allergic rhinitis $[4,5]$. LABAs are recommended only as add-on therapy to ICSs for moderate or severe asthma, but not for mild persistent asthma or allergic rhinitis, or as asthma monotherapy. Combinations of more than two medication classes are recommended only for severe persistent asthma. The 2006 GINA and 2007 NAEPP guidelines gave leukotriene modifiers a more prominent role in the treatment of asthma, particularly for those with concomitant allergic rhinitis, and restricted use of LABAs because of safety concerns $[2,3]$.

Although current asthma treatment guidelines recommend ICS + LABA as the first line therapy for patients with severe asthma, there are a lot of controversies $[6,7]$ over the potential safety issues [8] and an excess mortality rate in some studies [9]. The main concern is that chronic administration of LABAs may diminish the acute bronchodilating effect of short-acting beta-agonists [10-13], thus leaving the patient vulnerable to acute asthma attacks. Their use needs reappraisal [14], though LABAs are still advocated when taken in combination with an ICS [15]. However, there have been few observational studies of patient outcomes from the use of LABAs in combination with other long-term control asthma medications.

The PRAACTICAL (Patient-level Review of Asthma and Allergy Care Therapy Including Current Asthma treatment and Leukotrienes) study was a two-year retrospective preposttest study designed to assess the role of MON when added to an ICS in the treatment of patients with persistent asthma and allergic rhinitis [16]. The addition of MON was associated with reductions in asthma attacks, defined as an Emergency Room (ER) visit, hospitalization, or oral corticosteroid use for asthma. Since many patients in PRAACTICAL also received LABAs, this study provided an opportunity to assess outcomes in patients treated with combinations of MON, ICSs compared to patients who were treated with MON, ICSs and LABAs combination therapy.

In PRAACTICAL, patient groups diagnosed with mild and moderate asthma differed significantly in certain charac- teristics: mean age (31.6 versus 34.0 years); proportion with intermittent versus persistent allergic rhinitis (58.6\% versus $41.1 \%$ ); and the proportion being treated with LABAs on the index date (48.0\% versus $84.2 \%$ ). We analyzed the subgroup of patients having a physician's diagnosed with mild persistent asthma and concomitant allergic rhinitis. The objective was to determine differences in the likelihood of asthma attacks in patients treated with inhaled corticosteroid (ICS), long-acting beta-agonist (LABA), and montelukast (MON) (ICS/ LABA/MON) and patients treated with an inhaled corticosteroid (ICS) and montelukast (MON) (ICS/MON).

\section{Methods}

\section{I Study overview}

This was a post-hoc analysis of a cohort study of adults 15-55 years of age, with mild persistent asthma and concomitant allergic rhinitis, in three European countries (Italy, Spain, and Poland) from January 1, 1998 to December 31, 2003. Data were extracted from medical records with the collaboration of patients' health care providers. Patients already being treated with ICSs were included in the study if they began co-therapy with MON as part of their routine care during an index period between January 1, 1999 and December 31, 2002. Preindex and post-index periods of 12 months were defined prior to and following the initial, index prescription for MON. Patient characteristics in the 12-month pre-index period were recorded and study outcomes were determined for the 12-month post-index period. Further details of the study were described elsewhere [16]. Here, we report a post hoc analysis of the subset of patients with a physician diagnosis of mild persistent asthma, in which two treatment groups, ICS/LABA/MON and ICS/MON, were defined on the basis of their treatment in the postindex period.

\subsection{Patient population}

Patients in this analysis: had physician-diagnosed mild persistent asthma on the index date; had physician-diagnosed intermittent or persistent allergic rhinitis (these terms replace the previous 'seasonal' and 'perennial'); had prescription(s) for an ICS for at least 3 months during the 12-month post-index period, with or without a concomitant prescription(s) for a LABA for at least 3 months in the post-index period; started MON therapy as part of their routine care; and completed 12 months of MON therapy in the post-index period. The severities of asthma and seasonal allergic rhinitis on the index date were determined by physician diagnosis based on the GINA and ARIA guidelines that were provided to ensure that all patients had a diagnosis of mild persistent asthma on the index date. This is an ad hoc retrospective analysis of data from a cohort study, in which patients were asked to provide informed consent that authorized investigators to review 
their charts when the original cohort study was conducted.

\subsection{Outcome measures}

The study outcome variables were the numbers of prescriptions for asthma-and allergic rhinitis-related medications (short-acting beta-agonists, oral corticosteroids, antibiotics, and antihistamines) and numbers of asthmarelated hospitalizations and ER visits in the post-index period. A composite endpoint, an 'asthma attack', was defined as either use of an oral corticosteroid for asthma, or an asthma-related ER visit or hospitalization.

\subsection{Statistical analysis}

Two parallel groups, ICS/LABA/MON and ICS/MON, were defined on the basis of their treatment in the postindex period. Uni-variable analyses were used to compare the two treatment groups. T-test was used for continuous data and the chi-square test for discrete data in the comparisons of patient characteristics in the pre-index period and unadjusted study outcomes in the post-index period. Multiple logistic regression was used to compute the adjusted likelihood of asthma-and allergic rhinitis-related health care use in the post-index period in the ICS/LABA/ MON group relative to ICS/MON group. Adjustments were made for age, years of diagnosed allergic rhinitis, severity of allergic rhinitis, number of allergist visits, days on ICS or ICS/LABA treatment during the pre-index period, and days of ICS or ICS/LABA treatment during the post-index period. The analysis considered patients treated for at least three months with an ICS or an ICS/ LABA combination in the post-index period (all patients received 12 months of MON in the post-index period). A $\mathrm{p}$ value of 0.05 was considered to be statistically significant. All statistical analyses were performed using SAS v8.2 (Cary, NC, USA).

\section{Results}

\section{I Patient characteristics}

A total of 344 patients were included: 181 treated with ICS/MON and 163 with ICS/LABA/MON. Most patients had mild intermittent (36.1\%) or mild persistent (46.8\%) allergic rhinitis (Table 1). Patients had spent an average of 10.8 months on ICS therapy in the pre-index period 10.5 months in the ICS/MON group and 11.2 months in the ICS/LABA/MON group. Patients in the ICS/LABA/ MON group had spent an average of 8.0 months on LABA therapy in the pre-index period, while those in the ICS/ MON group had spent an average of 1.1 months. There were no statistically significant differences between the ICS/MON and ICS/LABA/MON groups in most characteristics. Compared with patients in the ICS/MON group, however, those in the ICS/LABA/MON group were slightly older (32.6 versus 30.4 years), had been diagnosed with allergic rhinitis for fewer years (8.4 versus 10.7 years), had more months on ICS therapy in the pre-index period (11.2 versus 10.5 months), and were less likely to visit an allergist in the post-index period (33.1\% versus $47.0 \%$ ). Finally, compared with patients in the ICS/MON group, those in the ICS/LABA/MON group had more months on therapy in the post-index period (11.2 versus 10.4 months).

\subsection{Asthma- and allergic rhinitis-related medical resource utilization in the post-index period}

Rates of medical resource use for asthma and allergic rhinitis in the 12-month post-index period were not significantly different in the ICS/MON and ICS/LABA/MON groups (Table 2). An asthma attack occurred in $4.4 \%$ of the ICS/MON group and $6.8 \%$ of the ICS/LABA/MON group. The adjusted likelihood of asthma and allergy medication use in the post-index period was not statistically significantly different in the ICS/LABA/MON and ICS/MON groups (Table 3). The likelihood of antibiotic use, however, was statistically significantly greater in the ICS/LABA/MON group ( $p=0.031$; Wald $\chi^{2}$ test $)$. The likelihood of an ER visit or of occurrence of an asthma attack was similar in the ICS/MON and ICS/LABA/MON groups (hospitalizations were too infrequent to be analyzed as a single independent variable).

\section{Discussion}

Meta-analyses of clinical trials indicate that the anti-asthmatic effects of both leukotriene modifiers and LABAs are additive to those of ICSs $[17,18]$. Clinical trials have not demonstrated additivity of the effects of LABAs and leukotriene modifiers on asthma symptoms, though addition of MON to ICS/LABA therapy reduces symptoms of allergic rhinitis $[19,20]$, and the addition of MON to a LABA or ICS/LABA combination improves airway hyperresponsiveness to methacholine or adenosine monophospate challenge [21,22].

The results of this study should be interpreted in the light of the following. The absence of an incremental effect of LABAs was inferred from the comparison of two parallel treatment groups. This study compared differences in the asthma-related outcomes of various combinations of asthma therapy (specifically ICS/LABA/MON vs ICS/ $M O N)$. Patients in the two groups differed in certain respects: patients in the ICS/MON/LABA group had slightly longer durations of ICS therapy in the pre-index and post-index periods, and appeared to have a lesser burden of allergic rhinitis (the elapsed time since diagnosis of allergic rhinitis was shorter, and the likelihood of visiting an allergist in the pre-index period was lower). We adjusted for differences between the two patient groups by multivariate regression modeling. Patients in the ICS/ MON/LABA group had a greater adjusted odds of using antibiotics in the post-index period, presumably reflecting 
Table I: Patient characteristics*

\begin{tabular}{|c|c|c|c|}
\hline & ICS/MON & ICS/LABA/MON & All Patients \\
\hline Patient N (\%) & $|8|(52.6 \%)$ & $163(47.4 \%)$ & $344(100.0 \%)$ \\
\hline Years of age $\ddagger$ & $30.4 \pm 9.3$ & $32.6 \pm 9.4$ & $31.5 \pm 9.4$ \\
\hline Male sex & $82(45.3 \%)$ & $69(42.6 \%)$ & $151(44.0 \%)$ \\
\hline Current smoker & $6(3.3 \%)$ & $10(6.1 \%)$ & $16(4.7 \%)$ \\
\hline Years since asthma diagnosed & $8.5 \pm 7.6$ & $8.0 \pm 7.7$ & $8.3 \pm 7.7$ \\
\hline Years since allergic rhinitis diagnosed $\ddagger$ & $10.7 \pm 8.2$ & $8.4 \pm 7.7$ & $9.6 \pm 8.1$ \\
\hline \multicolumn{4}{|l|}{ Allergic rhinitis severity } \\
\hline Mild intermittent & $60(33.2 \%)$ & $64(39.3 \%)$ & $124(36.1 \%)$ \\
\hline Mild persistent & $87(48.1 \%)$ & 74 (45.4\%) & $161(46.8 \%)$ \\
\hline Moderate-severe intermittent & $26(14.4 \%)$ & 15 (9.2\%) & $41(11.9 \%)$ \\
\hline Moderate-severe persistent & $8(4.4 \%)$ & $10(6.1 \%)$ & $18(5.2 \%)$ \\
\hline \multicolumn{4}{|l|}{ Months on therapy in prior 12 months } \\
\hline ICS $\ddagger$ & $10.5 \pm 3.4$ & $11.2 \pm 2.4$ & $10.8 \pm 3.0$ \\
\hline ICS/LABA $\ddagger$ & $1.1 \pm 3.2$ & $8.0 \pm 5.2$ & $4.4 \pm 5.5$ \\
\hline \multicolumn{4}{|c|}{ Asthma- and allergic rhinitis-related medical resource use in prior 12 months } \\
\hline Short-acting beta-agonist & $155(85.6 \%)$ & I $30(79.8 \%)$ & $285(82.9 \%)$ \\
\hline Oral corticosteroids & $21(11.6 \%)$ & $24(14.7 \%)$ & $45(13.1 \%)$ \\
\hline Antibiotics & $38(21.0 \%)$ & $44(27.0 \%)$ & $82(23.8 \%)$ \\
\hline Antihistamines & $129(7 \mid .3 \%)$ & $104(63.8 \%)$ & $233(67.7 \%)$ \\
\hline Allergist visitł & $85(47.0 \%)$ & $54(33.1 \%)$ & $139(40.4 \%)$ \\
\hline Pulmonologist visit & $\mathrm{I}(0.6 \%)$ & $\mathrm{I}(0.6 \%)$ & $2(0.6 \%)$ \\
\hline Emergency Room visit & $34(18.8 \%)$ & $23(14.1 \%)$ & $57(16.6 \%)$ \\
\hline Hospitalization & $7(3.9 \%)$ & $3(1.8 \%)$ & $10(2.9 \%)$ \\
\hline Asthma attack $\dagger$ & $49(27.1 \%)$ & $44(27.0 \%)$ & $93(27.0 \%)$ \\
\hline Months on therapy in 12-month follow-up $\ddagger$ & $10.5 \pm 2.9$ & $11.4 \pm 1.9$ & $10.9 \pm 2.5$ \\
\hline
\end{tabular}

*Values represent patient $\mathrm{N}(\%)$ or mean $\pm \mathrm{SD}$. $\dagger$ An asthma attack was defined as use of an oral corticosteroid, an asthma-related $\mathrm{ER}$ visit, or an asthma-related hospitalization. $\ddagger \mathrm{P}<0.05$ for ICS/MON compared with ICS/LABA/MON. 
Table 2: Rates of asthma- and allergic rhinitis-related medical resource use in the post-index period*

\begin{tabular}{|c|c|c|c|}
\hline & $\begin{array}{l}\text { ICS/MON } \\
(N=181)\end{array}$ & $\begin{array}{c}\text { ICS/LABA/MON } \\
(N=163)\end{array}$ & $\begin{array}{l}\text { All Patients } \\
(\mathrm{N}=344)\end{array}$ \\
\hline Short-acting beta-agonist & I35 (74.6\%) & 117 (71.8\%) & $252(73.3 \%)$ \\
\hline Oral corticosteroids & $2(1.1 \%)$ & $6(3.7 \%)$ & $8(2.3 \%)$ \\
\hline Antibiotics & $20(11.1 \%)$ & $26(16.0 \%)$ & $46(13.4 \%)$ \\
\hline Antihistamines & $84(46.4 \%)$ & 67 (4I.I\%) & $|5|(43.9 \%)$ \\
\hline ER visit & 7 (3.9\%) & $2(1.2 \%)$ & $9(2.6 \%)$ \\
\hline Hospitalization & I $(0.6 \%)$ & $4(2.5 \%)$ & $5(1.5 \%)$ \\
\hline Asthma attack $\dagger$ & $8(4.4 \%)$ & II (6.8\%) & $19(5.5 \%)$ \\
\hline
\end{tabular}

*Values represent patient $\mathrm{N}(\%)$. † An asthma attack was defined as use of an oral corticosteroid, an asthma-related ER visit, or an asthma-related hospitalization.

inappropriate prescribing and a perceived need for additional therapies in these patients. Although small, the proportion of asthma attacks differed in the two groups with the ICS/LABA/MON group experiencing more as compared to ICS/MON group. Data from this study provided evidence of differences between the two therapy groups.

Table 3: Adjusted likelihood of asthma- and allergic rhinitisrelated medical resource use in the post-index period with ICS/ LABA/MON relative to ICS/MON. *

\begin{tabular}{lc}
\hline & Odds Ratio $(95 \% \mathrm{Cl})$ \\
\hline Short-acting beta-agonist use & All patients $(\mathrm{N}=344) \dagger$ \\
\hline Oral corticosteroids use & $1.55(0.79-3.03)$ \\
\hline Antibiotics use & $2.00(0.26-15.4)$ \\
\hline Antihistamines use & $2.49(1.09-5.70)$ \\
\hline ER visit & $0.75(0.40-1.41)$ \\
\hline Asthma attack $\ddagger$ & $0.85(0.11-6.67)$ \\
\hline
\end{tabular}

* after adjusting for age, years of diagnosed allergic rhinitis, severity of allergic rhinitis, number of allergist visits, days on ICS or ICS/LABA treatment during the pre-index period, and days of ICS or ICS/LABA treatment during the post-index period

† Patients treated with 12 months of MON and at least 3 months with a LABA and/or an ICS (observed mean 10.7 months of treatment) in the post-index period.

t Patients treated with 12 months of all three drug classes.

$\ddagger$ An asthma attack was defined as either use of an oral corticosteroid, an asthma-related ER visit, or an asthma-related hospitalization.
Due to the rare occurrence of asthma attacks, studies with larger sample sizes are needed to confirm our findings.

\section{Conclusion}

Based on this observational study, patients with comorbid asthma and allergic rhinitis receiving ICS/MON combination therapy, and those receiving ICS/MON/LABA combination therapy had similar rates of asthma attacks.

\section{Competing interests}

Dr. Dal Negro and Dr. Borderias were consulting for Merck \& Co., Inc. Drs. Zhang, Sazonov, Fan and Taylor are employees and stock holders of Merck \& Co., Inc., a manufacturer of respiratory drugs.

\section{Authors' contributions}

RWDN, LB, MG, SV and ST contributed to the study design and conceptualization. RWDN, LB acquired data. QZ conducted statistical analysis. TF, SV, QZ, and ST interpreted the study results. And QZ, TF and ST prepared the manuscript.

\section{Note}

A preliminary version of this material was presented at the American Thoracic Society's Annual International Conference, May 19-24, 2006, San Diego, CA, USA

\section{Acknowledgements}

Funding for this study was provided by Merck \& Co., Inc., and several of the authors (Q. Zhang, V. Sazonov Kocevar, and S.D. Taylor) are employees of Merck \& Co., Inc. The authors acknowledge the medical writing assistance of SCRIBCO.

\section{References}

I. Bousquet J, Van Cauwenberge P, Khaltaev N: Allergic rhinitis and its impact onasthma. J Allergy Clin Immunol 200I, I08:SI47-334. 
2. Global Initiative for Asthma: Global strategy for asthma management and prevention, 2006.

3. Guidelines for the Diagnosis and Management of Asthma. Expert Panel Report 3 Full Report: National Heart, Lung, and Blood Institute. National Asthma Education and Prevention Program; 2007.

4. Chervinsky P, Philip G, Malice MP, Bardelas J, Nayak A, Marchal JL, van Adelsberg J, Bousquet J, Tozzi CA, Reiss TF: Montelukast for treating fall allergic rhinitis: effect of pollen exposure in $\mathbf{3}$ studies. Ann Allergy Asthma Immunol 2004, 92:367-73.

5. Philip G, Nayak AS, Berger WE, Leynadier F, Vrijens F, Dass SB, Reiss TF: The effect of montelukast on rhinitis symptoms in patients with asthma and seasonal allergic rhinitis. Current medical research and opinion 2004, 20:1549-58.

6. Martinez FD: Safety of long-acting beta-agonists - an urgent need to clear the air. The New England journal of medicine 2005, 353:2637-9.

7. Glassroth J: The role of long-acting beta-agonists in the management of asthma: analysis, meta-analysis, and more analysis. Annals of internal medicine 2006, I 44:936-7.

8. Walters EH, Gibson PG, Lasserson TJ, Walters JA: Long-acting beta2-agonists for chronic asthma in adults and children where background therapy contains varied or no inhaled corticosteroid. Cochrane Database Syst Rev 2007:CD00I 385.

9. Hasford J, Virchow JC: Excess mortality in patients with asthma on long-acting beta2-agonists. Eur Respir J 2006, 28:900-2.

10. Bhagat R, Kalra S, Swystun VA, Cockcroft DW: Rapid onset of tolerance to the bronchoprotective effect of salmeterol. Chest 1995, 108: 1235-9.

I I. Lipworth BJ, Aziz I: A high dose of albuterol does not overcome bronchoprotective subsensitivity in asthmatic subjects receiving regular salmeterol or formoterol. J Allergy Clin Immunol 1999, 103:88-92.

12. Aziz I, Lipworth B]: In vivo effect of albuterol on methacholinecontracted bronchi in conjunction with salmeterol and formoterol. J Allergy Clin Immunol 1999, 103:816-22.

13. Woude HJ van der, Winter TH, Aalbers R: Decreased bronchodilating effect of salbutamol in relieving methacholine induced moderate to severe bronchoconstriction during high dose treatment with long acting beta2 agonists. Thorax 200I, 56:529-35.

14. Lipworth B]: Long-acting beta(2)-adrenoceptor agonists: a smart choice for asthma? Trends Pharmacol Sci 2007, 28:257-62.

15. Ernst P, Mclvor A, Ducharme FM, Boulet LP, FitzGerald M, Chapman KR, Bai T, Canadian Asthma Guideline Group: Safety and effectiveness of long-acting inhaled beta-agonist bronchodilators when taken with inhaled corticosteroids. Annals of internal medicine 2006, 145:692-4.

16. Borderias L, Mincewicz G, Paggiaro PL, Guilera M, Sazonov Kocevar $\mathrm{V}$, Taylor SD, Badia X: Asthma control in patients with asthma and allergic rhinitis receiving add-on montelukast therapy for 12 months: a retrospective observational study. Current medical research and opinion 2007, 23:721-30.

17. Ducharme F, Schwartz Z, Hicks G, Kakuma R: Addition of anti-leukotriene agents to inhaled corticosteroids for chronic asthma. Cochrane Database Syst Rev 2004:CD003I33.

18. Gibson PG, Powell H, Ducharme FM: Differential effects of maintenance long-acting beta-agonist and inhaled corticosteroid on asthma control and asthma exacerbations. I Allergy Clin Immunol 2007, I I 9:344-50.

19. Robinson DS, Campbell D, Barnes PJ: Addition of leukotriene antagonists to therapy in chronic persistent asthma: a randomised double-blind placebo-controlled trial. Lancet 200I, 357:2007-II.

20. Nathan RA, Yancey SW, Waitkus-Edwards K, Prillaman BA, Stauffer JL, Philpot E, Dorinsky PM, Nelson HS: Fluticasone propionate nasal spray is superior to montelukast for allergic rhinitis while neither affects overall asthma control. Chest 2005, 128:1910-20.

21. Currie GP, Lee DK, Dempsey OJ, Fowler S], Cowan LM, Lipworth B: A proof of concept study to evaluate putative benefits of montelukast in moderate persistent asthmatics. $\mathrm{Br} / \mathrm{Clin} \mathrm{Phar}-$ macol 2003, 55:609-I5.

22. Currie GP, Lee DK, Haggart K, Bates CE, Lipworth BJ: Effects of montelukast on surrogate inflammatory markers in corti- costeroid-treated patients with asthma. Am J Respir Crit Care Med 2003, 167:1232-8.

\section{Pre-publication history}

The pre-publication history for this paper can be accessed here:

http://www.biomedcentral.com/1471-2466/9/10/prepub
Publish with Bio Med Central and every scientist can read your work free of charge

"BioMed Central will be the most significant development for disseminating the results of biomedical research in our lifetime. "

Sir Paul Nurse, Cancer Research UK

Your research papers will be:

- available free of charge to the entire biomedical community

- peer reviewed and published immediately upon acceptance

- cited in PubMed and archived on PubMed Central

- yours - you keep the copyright 